\title{
Application of an in-wheel direct drive motor based on switched reluctance motors for low-power electric vehicles
}

\author{
N USTKOYUNCU \\ Department of Electrical and Electronics Engineering, Faculty of Engineering, Erciyes University, \\ 38039 Kayseri, Turkey \\ e-mail: nurettinu@erciyes.edu.tr
}

MS received 19 July 2017; revised 3 April 2018; accepted 1 August 2018; published online 2 January 2019

\begin{abstract}
This paper presents application of a switched reluctance motor with exterior rotor as an in-wheel direct drive motor for low-power electric vehicles (EVs). A prototype system is realized for experimental studies. Both analytical method and finite-element analysis (FEA) are used in this research to obtain characteristics of the motor. The results of the FEA and analytical calculations are presented, and compared to experimental results. The obtained test and simulation results show that the proposed system is suitable for lowpower and low-cost EVs.
\end{abstract}

Keywords. Switched reluctance motor; in-wheel direct drive motor; electric vehicle.

\section{Introduction}

Switched reluctance motor (SRM) drives are very attractive candidates for electric vehicles (EVs) due to their simple and rugged construction, low mass production cost, excellent torque-speed characteristics, high torque density, high operating efficiency and inherent fault tolerance $[1,2]$. Inwheel direct drive electric motors provide many advantages to EVs such as increased efficiency, simple mechanical structure, reduced cost and vehicle weight by eliminating many mechanical parts of the vehicle such as gear box etc. In addition, in-wheel motor drives have high torque to weight and volume ratios, which are required to accelerate the vehicle and to provide a high torque at low speeds in general [3].

As can be seen in the literature, different motor types have been used for in-wheel applications and most of them are permanent magnet (PM) motors. Although PM motors have higher torque density and lower weight values, magnets limit the speed range of motors [4]. In addition, the price and the supply of the PMs with rare-earth material such as neodymium and dysprosium are serious problems for EVs. Therefore, there is an increasing interest in rareearth-free electric motors for these vehicles [5]. Although there are some problems in SRMs such as low torque density, noise, vibration and torque ripple, many studies have been presented to overcome these problems in the literature $[2,3,5,6]$. Therefore, the low cost and the operation in a wide speed range with high efficiency make the SRM a very suitable choice for in-wheel direct drive systems.
The analysis procedure of the proposed SRM is realized using an analytical approach and finite-element analysis (FEA) in this study. Analytical methods use simplifying physical assumptions. However, these methods are not very accurate to calculate magnetic characteristics of the SRMs and most of these disadvantages of the analytical techniques can be eliminated using FEA as a numerical method [7-10]. As a result, both of these techniques are used and results of these techniques are presented and compared in the study.

This work presents application of the in-wheel direct drive motor based on SRM and the organization of this paper is as follows. The construction and details of the proposed SRM are presented in section 2. Section 3 gives some information about the analytical method and numerical analysis of the motor. Section 4 covers the results of analyses and comparing them to experimental measurements and section 5 presents the conclusions of the study.

\section{Details of the proposed in-wheel direct drive motor}

The proposed SRM structure has three phases with 8 and 6 numbers of poles for rotor and stator, respectively, as given in figure 1. The stator and rotor platforms of the prototype motor are manufactured using laminated steel sheets. The rotor part of the motor is placed on an aluminium cover that contains two different side constituents because of their functionalities, and the appearance of one side of the cover is shown in figure 2. Some mechanical and electrical 


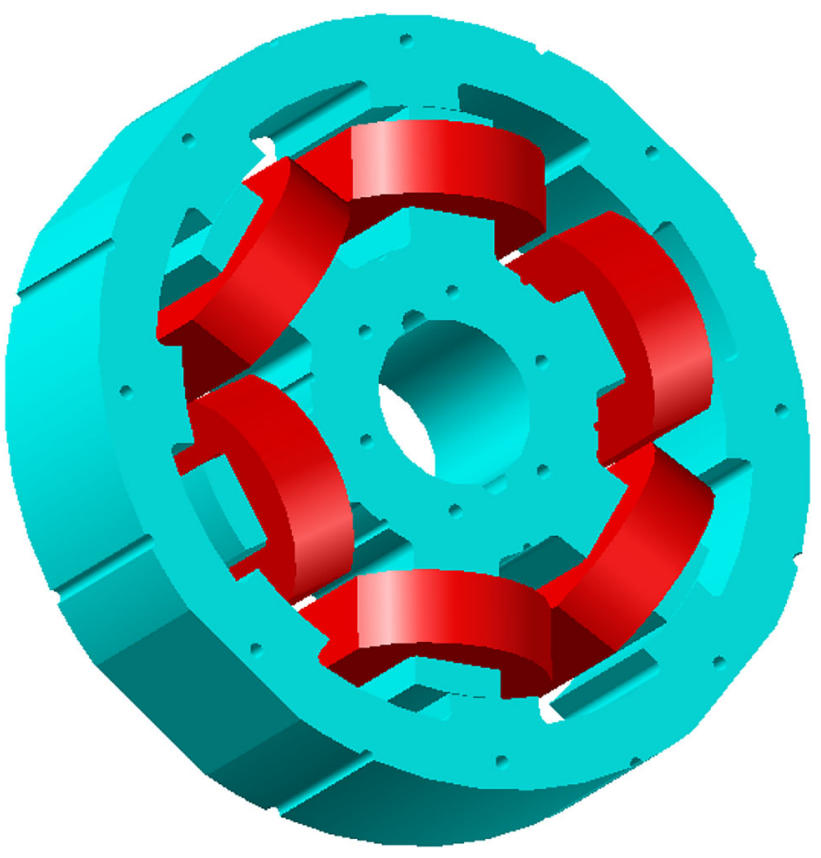

Figure 1. Three-dimensional model of the proposed three-phase exterior rotor SRM.

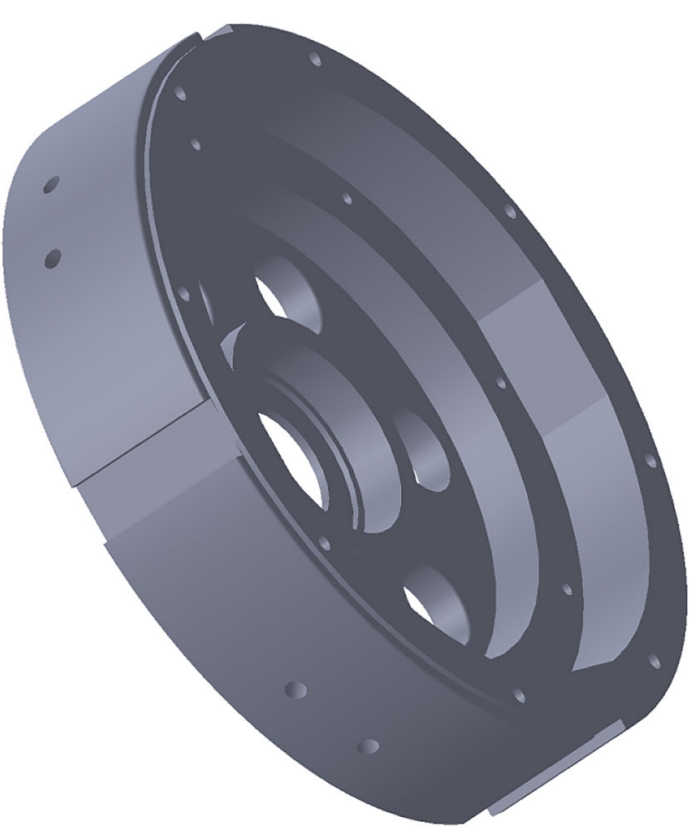

Figure 2. Three-dimensional model of one side of the cover.

parameters of the proposed SRM are summarized in table 1.

The prototype motor has an exterior-rotor structure and is designed for low-speed direct drive applications for lowcost EVs and it can provide almost $1-\mathrm{kW}$ power to the vehicle at its operating speed.
Table 1. Parameters of the prototype SRM.

\begin{tabular}{lc}
\hline Phase number & 3 \\
Stator pole numbers & 6 \\
Rotor pole numbers & 8 \\
Shaft radius (mm) & 22.5 \\
Rotor inner radius (mm) & 80.25 \\
Rotor outer radius (mm) & 102.5 \\
Stator inner radius (mm) & 42.5 \\
Stator outer radius (mm) & 80 \\
Air gap (mm) & 0.25 \\
Stator pole arc (deg) & 18 \\
Rotor pole arc (deg) & 19 \\
Stack length (mm) & 50 \\
Number of turns per pole & 32 \\
Rated voltage (V) & 48 \\
Rated current (A) & 26 \\
Rated power (W) & 1020 \\
Rated speed (rpm) & 835 \\
\hline
\end{tabular}

\section{Analytical approach and numerical analysis of the SRM}

\subsection{Analytical approach}

In this paper, a simple analytical method given in detail in [11-14] is used to obtain incremental phase inductance profile of the proposed SRM. The incremental phase inductance variation can be represented using a Fourier series; the first three terms are as given in Eq. (1) by this method:

$$
L(i, \theta)=L_{0}(i)+L_{1}(i) \cos \left(N_{r} \theta\right)+L_{2}(i) \cos \left(2 N_{r} \theta\right)
$$

where $N_{r}, \theta$ and $i$ are the number of rotor poles, rotor position and phase current of the motor, respectively. The first three terms of the Fourier series $L_{0}, L_{1}$ and $L_{2}$ can be calculated using inductance values at the aligned and unaligned positions and the inductance value at the midway between the aligned and unaligned positions for different phase currents. These inductance values are taken from the FEA results of the SRM to make a fair comparison to FEA results for different phase currents in the paper.

\subsection{Finite-element analysis}

Important characteristics of SRMs such as torque profiles, inductance and flux linkage characteristics as a function of position and current can be obtained using FEA. In general, solution positions are chosen from complete unaligned to aligned position in small rotation for different phase currents to obtain static characteristics of SRMs.

Levels of the excitation current are selected to be in steps of $1 \mathrm{~A}$, from 1 to $50 \mathrm{~A}$, in this study and the flux distributions of the SRM obtained for the unaligned and aligned 


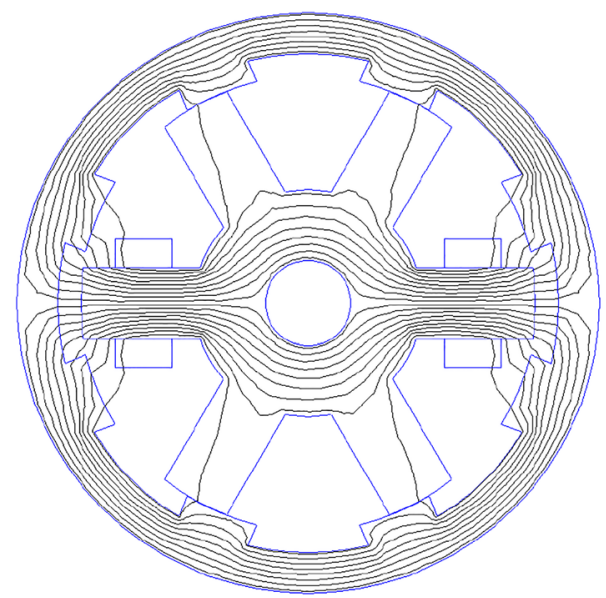

(a)

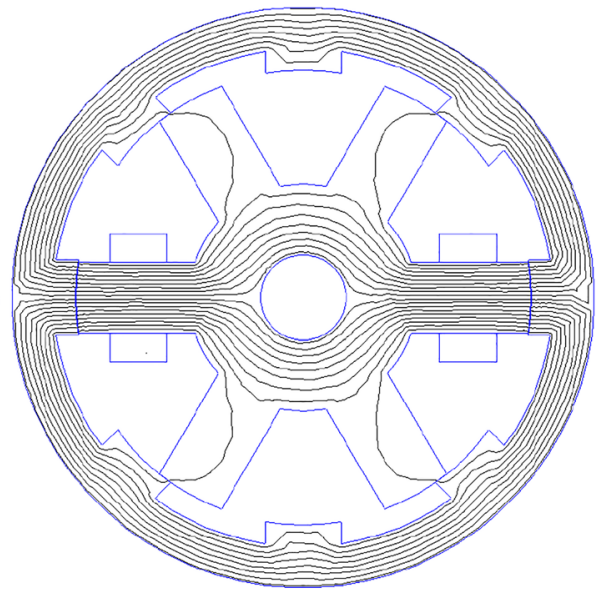

(b)

Figure 3. Flux distribution of the prototype SRM: (a) unaligned position and (b) aligned position.

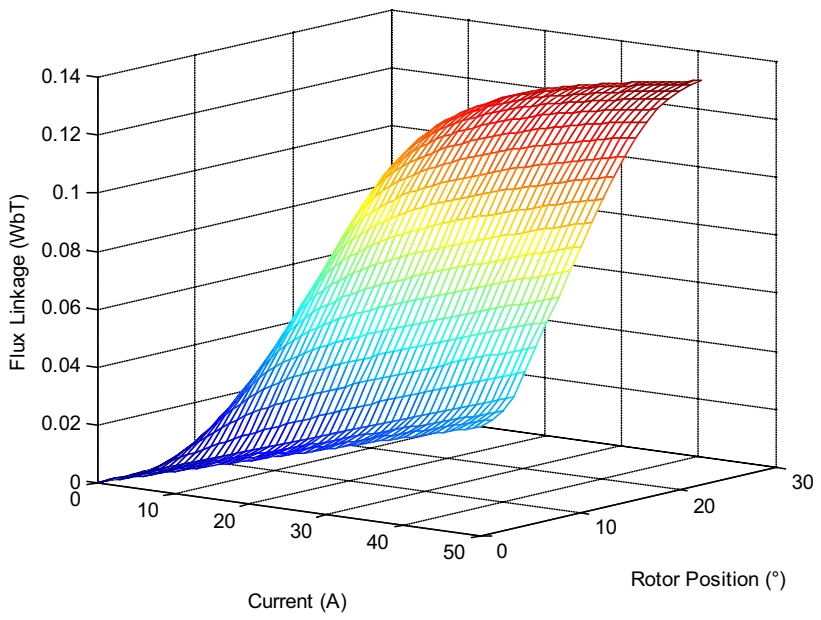

Figure 4. Flux linkage-rotor position and current relationship of the SRM.

positions are shown in figure $3 \mathrm{a}$ and $\mathrm{b}$, respectively. In addition, figure 4 shows the obtained flux linkage-current relationship of the motor at different rotor positions.

\section{Analytical calculations, FEA results and experimental measurements}

The experimental set-up for the prototype exterior rotor SRM is shown in figure 5. A driver unit is designed to drive the SRM for desired conditions. The driver unit has two main components as power and control cards. Insulated gate bipolar transistors (IGBTs) are used for the realized asymmetric bridge converter to drive the prototype motor and a 48-V DC supply voltage is used. The driver unit uses a DSPIC30F4011 microcontroller in the controller board. In addition, the rotor position is sensed by three Hall effect

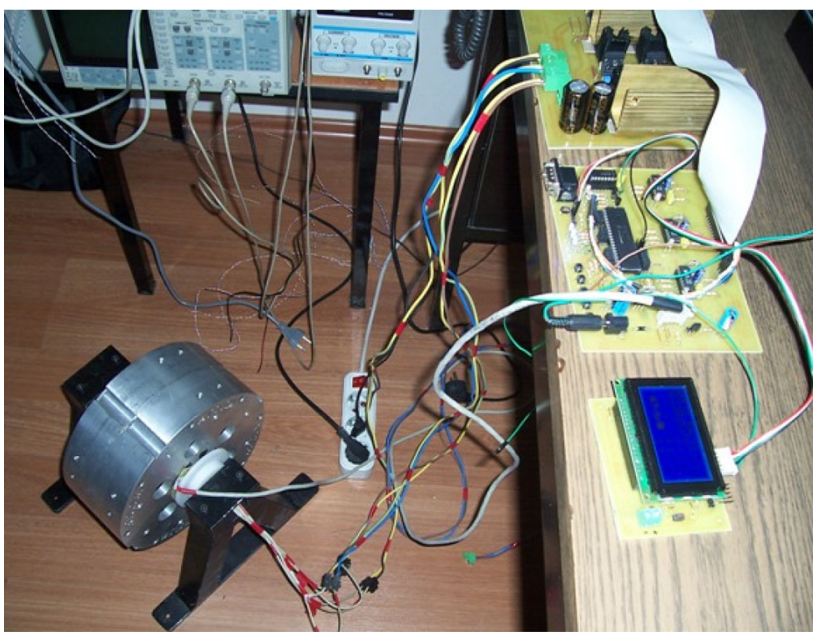

Figure 5. Experimental set-up for the prototype SRM.

sensors activated by magnets placed on the aluminium cover of the motor.

Static torque profile of the SRM obtained using FEA is shown in figure 6. Maximum excitation current of the active phase is $50 \mathrm{~A}$, as mentioned before.

Comparison of the inductance results by the analytical method and FEA is shown in figure 7. When the analytical calculation and FEA results are compared to each other, it is observed that there are only very minor differences between the values.

Speed-torque-efficiency characteristics of the motor are shown in figure 8 as a simulation result. As shown in figure 8, the prototype motor is designed to be operated at $800 \mathrm{rpm}$ base speed with $12 \mathrm{Nm}$ torque value; it has almost $1-\mathrm{kW}$ output power when it operates at rated speed with $82 \%$ efficiency.

The current controller is used to obtain these characteristics for simulations. Minimum and maximum current 


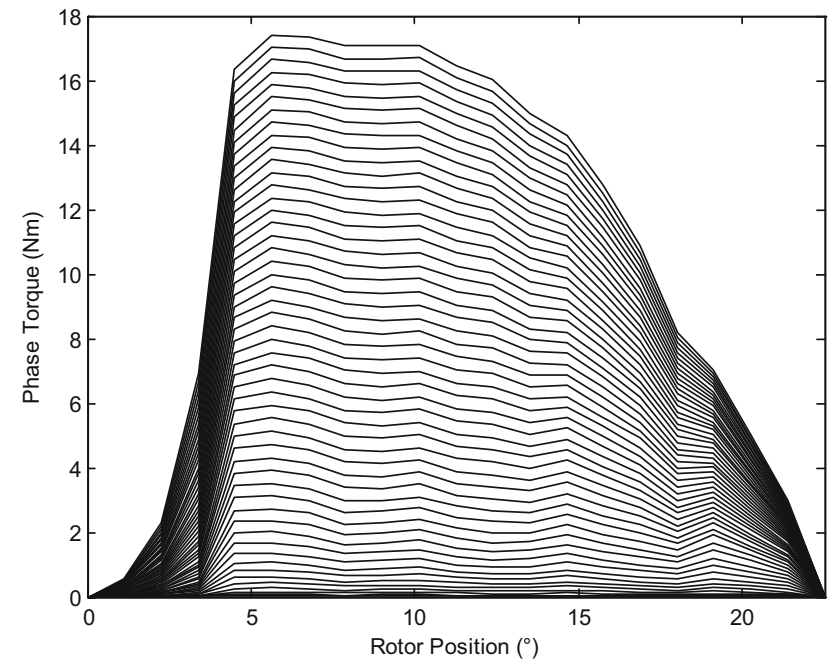

Figure 6. Torque profile of the SRM.

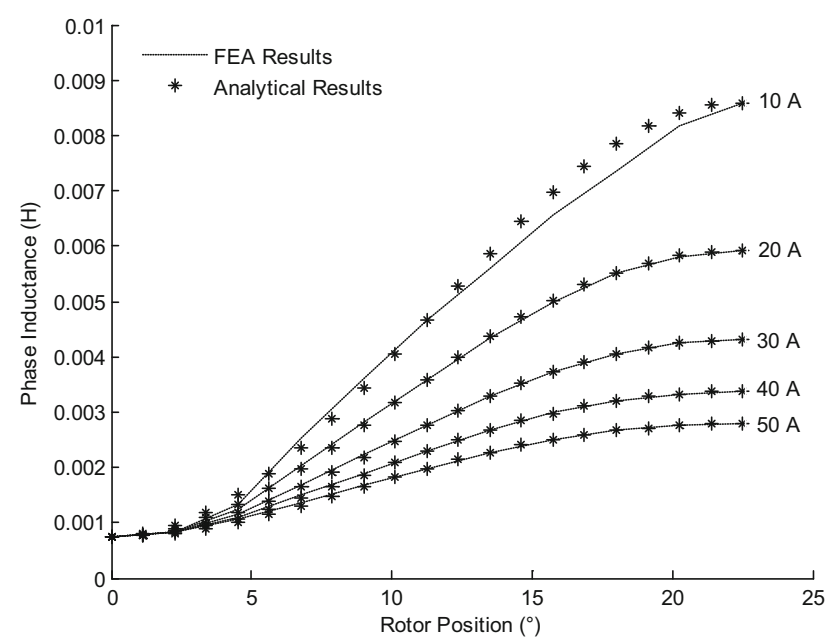

Figure 7. Comparing the inductance results of FEA and analytical method.

limit levels are 40 and $42 \mathrm{~A}$, respectively. In addition, turnon angle is $3.75^{\circ}$ and turn-off angle is $18.75^{\circ}$ in these simulations. Phase current waveforms and output torque of the motor at 850-rpm speed are shown in figures 9 and 10, respectively.

In addition to analytical and numerical results, torque profiles of the motor have been measured experimentally to compare with FEA results for several levels of phase excitation current as shown in figure 11 .

Torque measurement is a very difficult process for motors with exterior rotors. Special hardware and structures should be used for this purpose, and to measure values sensitively. Although the last experimental measurement is realized with 10-A phase current, because of limitation of the used hardware in this study, there are some minor and acceptable differences between FEA and experimental results as shown in figure 11 .

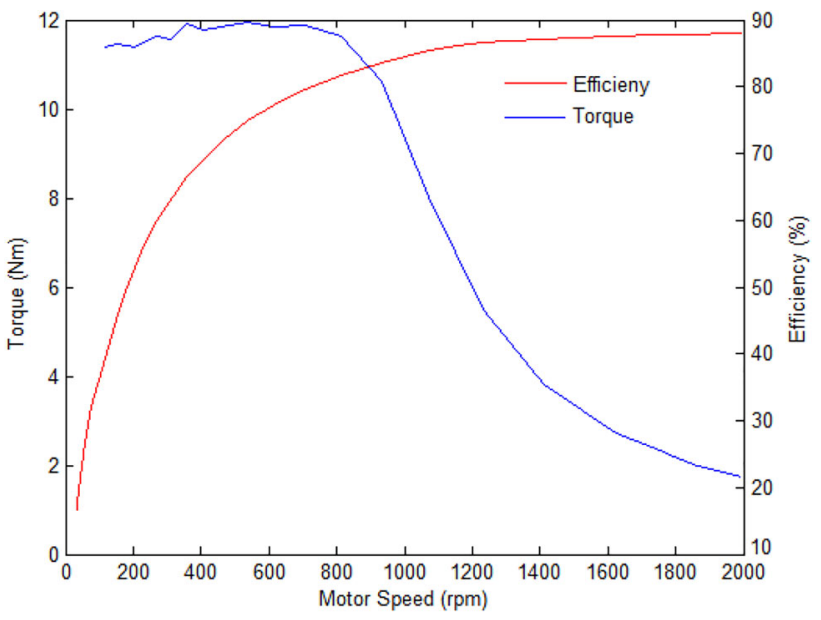

Figure 8. Speed-torque-efficiency characteristics of the SRM.

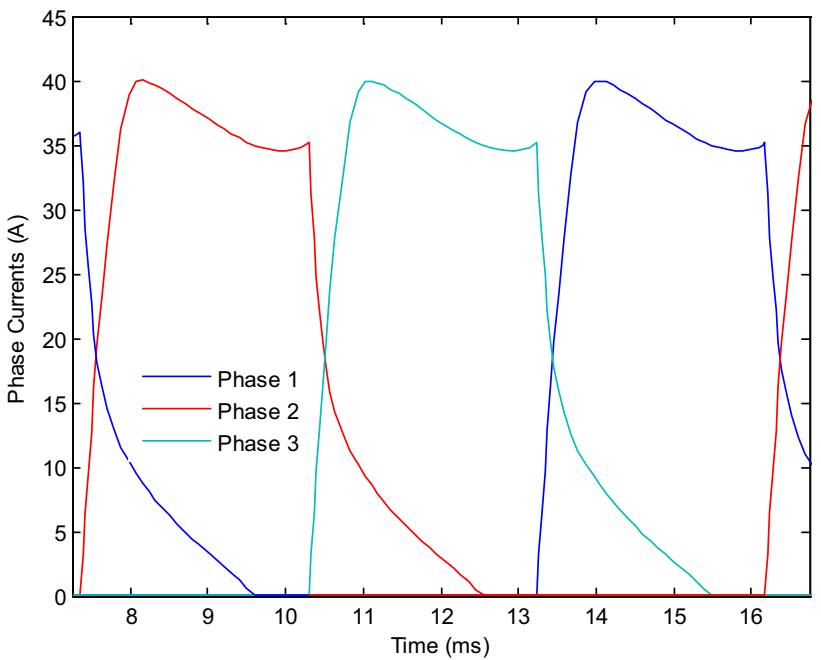

Figure 9. Phase current waveforms at 850-rpm motor speed.

In addition, figure 12 shows obtained inductance profiles of the SRM using FEA and analytical approach, and also experimentally measured torque values. Experimental results are derived from measured torque values at 10-A phase current except for the unaligned inductance value. This inductance value is measured using an LCR meter.

Scope appearance of phase voltage and current waveforms is shown in figure 13. The motor is operated almost at the rated speed and controlled using a voltage controller at no load condition for this measurement. Phase current is obtained using a resistor and measured from $\mathrm{CH} 2$.

\section{Conclusions}

In this paper, an SRM with exterior rotor as an in-wheel direct drive motor for low-power EVs is presented and realized. Analysis procedure of the motor is realized with 


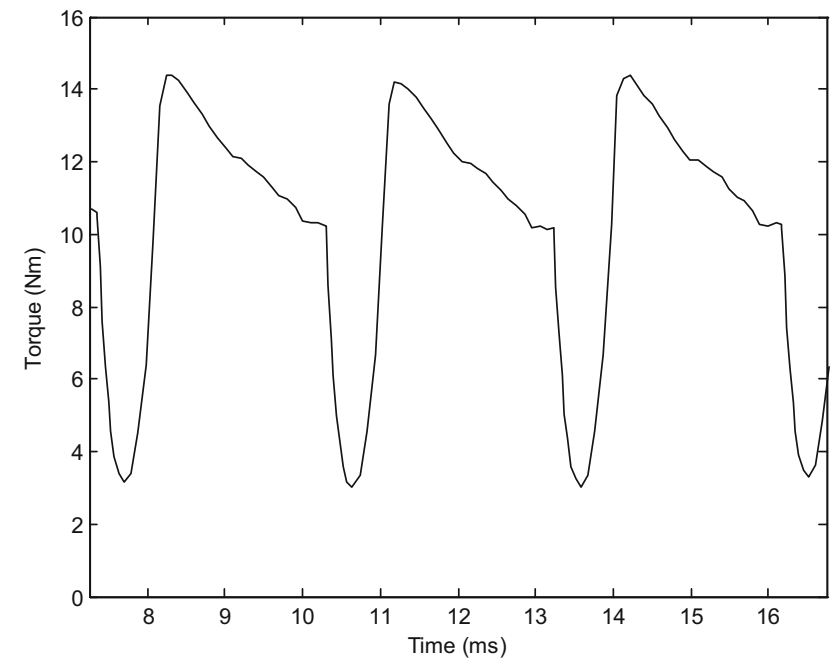

Figure 10. Torque of the motor at 850-rpm motor speed.

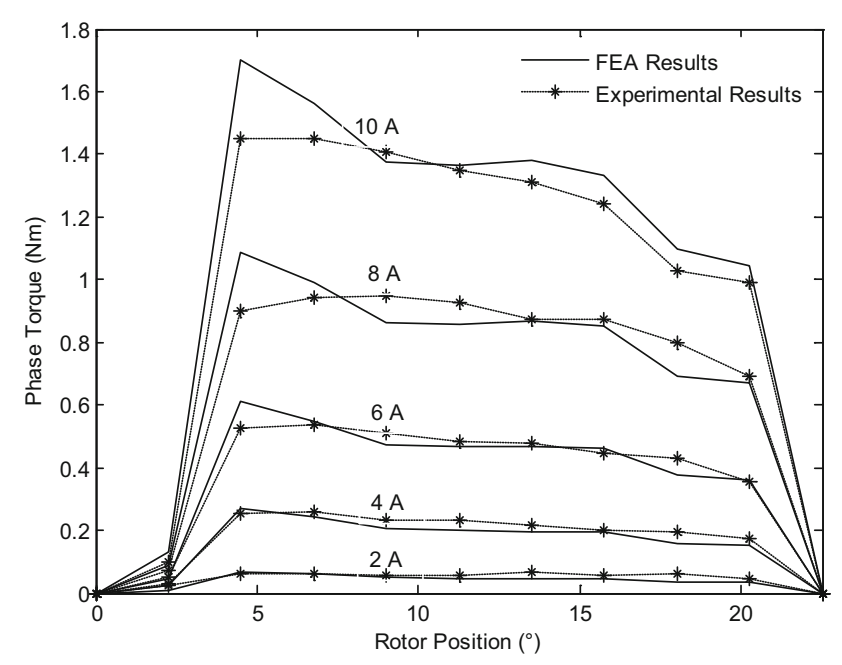

Figure 11. Phase torque profile of the SRM.

the use of analytical techniques and FEA prior to construction of the prototype SRM. In addition, experimental results are compared to these results. The prototype motor has almost a $1-\mathrm{kW}$ power at the base speed of $800 \mathrm{rpm}$. The proposed motor has some advantages such as low cost, high efficiency and simple structure and it is suitable for lowcost and low-power EVs such as electric golf carts and motorcycles. However, electric motors used in these types of EVs consist of PMs as in brushless DC (BLDC) or permanent magnet synchronous (PMS) motors in general and the magnet cost of these motors causes a very big disadvantage for low-cost EVs. The SRM proposed in the paper has almost less than a half production cost and similar efficiency values with a simpler structure compared with other motors mentioned earlier. The SRM drive has almost $82 \%$ efficiency at the rated speed and this value is sufficient compared to those of BLDC or PMS motors with

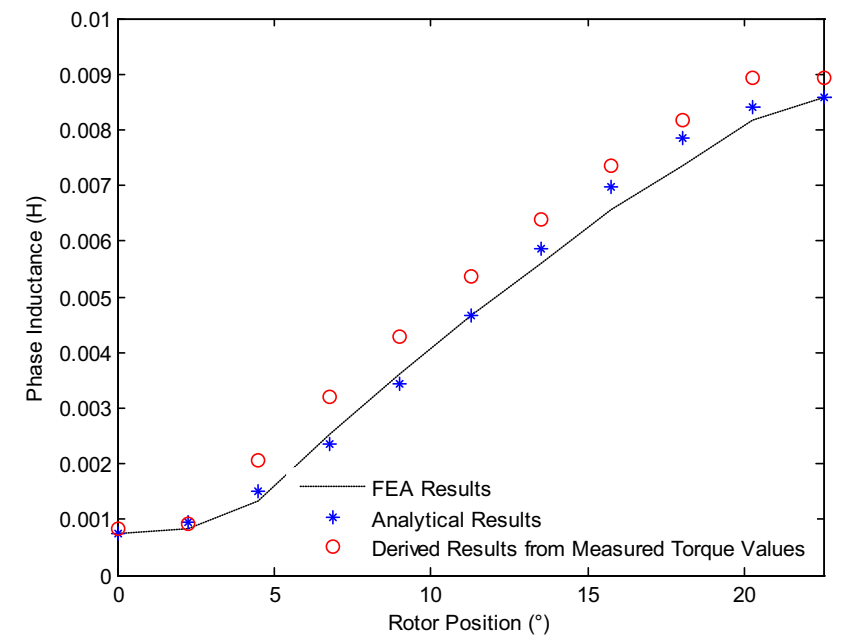

Figure 12. Comparing inductance profiles of the SRM for 10-A excitation current.

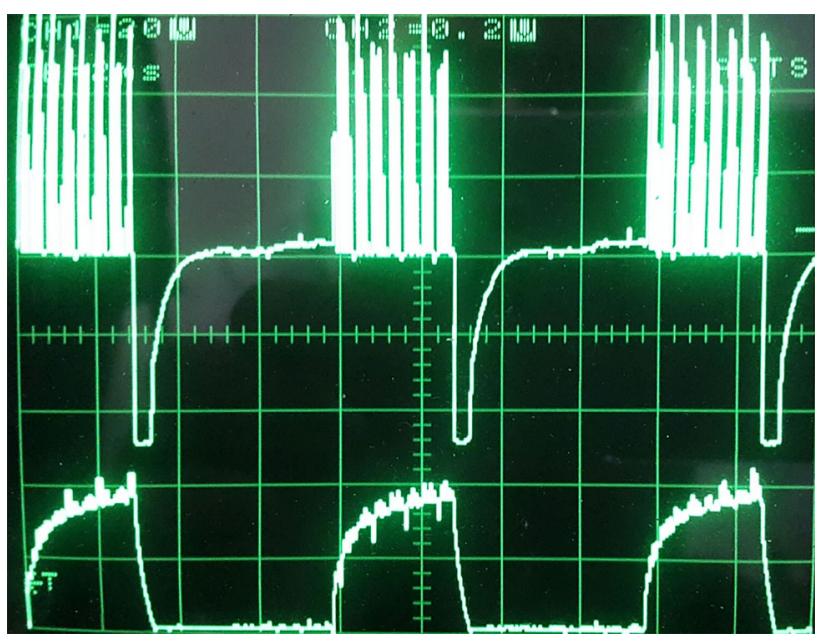

Figure 13. Scope appearance of phase voltage and current waveforms.

similar power ratio. Therefore, cost-effective vehicles can be commercialized using the proposed motor.

\section{Acknowledgements}

This study was supported by Ministry of Science, Industry and Technology in Republic of Turkey under the Grant No. 0329-TGSD-2013.

\section{References}

[1] Rahman K M, Fahimi B, Suresh G, Rajarathnam A V and Ehsani M 2000 Advantages of switched reluctance motor applications to EV and HEV: Design and control issues. IEEE Trans. Ind. Appl. 36(1): 111-121 
[2] Xue X D, Cheng K W E, Lin J K, Zhang Z, Luk K F, Ng T W and Cheung N C 2010 Optimal control method of motoring operation for SRM drives in electric vehicles. IEEE Trans. Veh. Technol. 50(3): 1191-1204

[3] Gottipati P, Dobzhanskyi O and Mendrela E A 2010 Inwheel brushless DC motor for a wheel chair drive. In: Proceedings of the International Conference on Power Electronics, Drives and Energy Systems (PEDES), pp. 1-4

[4] Cinar M A and Kuyumcu F E 2007 Design and drives simulation of an in-wheel switched reluctance motor for electric vehicle applications. In: Proceedings of the International Conference on Electrical Machines and Drives (IEMDC), pp. 50-54

[5] Takeno M, Chiba A, Hoshi N, Ogasawara S, Takemoto M and Rahman M A 2012 Test results and torque improvement of the $50-\mathrm{kW}$ switched reluctance motor designed for hybrid electric vehicles. IEEE Trans. Ind. Appl. 48(4): 1327-1334

[6] Schofield N, Long S A, Howe D and McClelland M 2009 Design of a switched reluctance machine for extended speed operation. IEEE Trans. Ind. Appl. 45(1): 116-122

[7] Lindsay J F, Arumugam R and Krishnan R 1986 Magnetic field analysis of a switched reluctance motor with multitooth per stator pole. Proc. Inst. Electric. Eng. 133(6): 347-353
[8] Fulton N N 1987 The application of CAD to switched reluctance drives. In: Proceedings of the Conference on Electrical Machines and Drives, pp. 275-279

[9] Radun A V 1995 Design considerations for the switched reluctance motor. IEEE Trans. Ind. Appl. 31(5): 1079-1087

[10] Omekanda A M, Broche C and Renglet M 1997 Calculation of the electromagnetic parameters of a switched reluctance motor using an improved FEM-BIEM application to different models for the torque calculation. IEEE Trans. Ind. Appl. 33(4): 914-918

[11] Suresh G, Fahimi B, Rahman K M and Ehsani M 1999 Inductance based position encoding for sensorless SRM drives. In: Proceedings of the IEEE Power Electronics Specialists Conference, pp. 832-837

[12] Gao H, Salmasi F R and Ehsani M 2004 Inductance modelbased position encoding for sensorless control of the switched reluctance motor drive at low speed. IEEE Trans. Power Electron. 19(6): 1568-1573

[13] Daldaban F and Ustkoyuncu N 2007 New disc type switched reluctance motor for high torque density. A novel linear switched reluctance motor for railway transportation systems. Energy Convers. Manag. 48(8): 2424-2431

[14] Daldaban F and Ustkoyuncu N 2010 A novel linear switched reluctance motor for railway transportation systems. Energy Convers. Manag. 51(3): 465-469 